\title{
Conferring on Religion: Notes from the 2010 Australasian Philosophy of Religion Association Conference
}

\author{
Morgan Luck
}

Published online: 24 December 2010

(C) Springer Science+Business Media B.V. 2010

In 2010, the third annual conference of the Australasian Philosophy of Religion Association (APRA) was held on the 17th and 18th of July at the University of Melbourne's Sidney Myer Asia Centre. Attracting 46 attendees travelling from as far away as the U.S.A. and the U.K., the conference once again provided an excellent opportunity for those interested in philosophy of religion to meet and learn from one another.

The proceedings were opened by APRA's first president, Dr. Bruce Langtry. With over 35 years of outstanding service to the field, Dr. Langtry is one of Australasia's most eminent philosophers of religion. APRA has benefited greatly from the time and energy that he devoted to this year's conference.

A total of 32 speakers presented papers on a range of topics over the course of the conference - four of which feature in this edition of Sophia. The keynote addresses were given by Prof. Raimond Gaita, Prof. Graham Oppy and Prof. Purushottama Bilimoria. Prof. Gaita's paper, entitled 'Love, Reason and Realism', examined Mark Wynn's discussion of the religious grounds for a certain type of moral goodness. Prof. Oppy's paper, entitled 'God and the Causal Order', investigates whether naturalistic explanations of the causal origin of the universe are more explanatorily powerful than theistic explanations. Prof. Bilimoria, in his paper 'Why is there Nothing rather than Something?', considers how the notion of Radical Nothingness underpins various eastern religious and philosophical cosmologies.

This year's conference was organized chiefly by Dr. Nick Trakakis with the support of Deakin University, Charles Sturt University and the University of Melbourne's Sidney Myer Asia Centre. Dr. Trakakis is one of the founding members of APRA, and his energy, experience and good will not only ensured an interesting and enjoyable conference this year, but has also helped to give the association the momentum needed to ensure its continuation.

In 2011, the APRA conference is to be held at the University of Auckland, New Zealand. The conference organizer is Dr. Chris Tucker, and APRA's new president will be Prof. John Bishop. We hope to see you there.

\footnotetext{
M. Luck $(\square)$

School of Humanities and Social Sciences, \& The Centre for Applied Philosophy and Public Ethics, Charles Sturt University, Locked Bag 588, Wagga Wagga, NSW 2678, Australia

e-mail: moluck@csu.edu.au
} 